\title{
SHARP WILKER AND HUYGENS TYPE INEQUALITIES FOR TRIGONOMETRIC AND INVERSE TRIGONOMETRIC FUNCTIONS
}

\author{
Bo ZHANG AND CHAO-PING CHEN
}

Abstract. In this paper, we prove Wilker and Huygens type inequalities for inverse trigonometric functions. This solves two conjectures proposed by Chao-Ping Chen. Also, we present new sharp Wilker and Huygens type inequalities for trigonometric functions.

Mathematics subject classification (2010): 26 D05.

Keywords and phrases: Inequalities, trigonometric functions.

\section{REFERENCES}

[1] G. D. Anderson, S.-L. Qiu, M. K. Vamanamurthy and M. Vuorinen, Generalized elliptic integral and modular equations, Pacific J. Math. 192 (2000), 1-37.

[2] G. D. Anderson, M. K. Vamanamurthy and M. Vuorinen, Conformal Invariants, Inequalities, and Quasiconformal Maps, New York, 1997.

[3] G. D. Anderson, M. K. Vamanamurthy and M. Vuorinen, Monotonicity of Some Functions in Calculus, https://www.math.auckland.ac.nz/Research/Reports/Series/538.pdf.

[4] A. BARICZ AND J. SÁNDOR, Extensions of generalized Wilker inequality to Bessel functions, J. Math. Inequal. 2 (2008), 397-406.

[5] C.-P. CHEN, Sharp Wilker-and Huygens-type inequalities for inverse trigonometric and inverse hyperbolic functions, Integral Transforms Spec. Funct. 23, 12 (2012), 865-873.

[6] C. P. Chen AND W.S. Cheung, Sharpness of Wilker and Huygens type inequalities, J. Inequal. Appl. 2012, 72, http://www . journalof inequalitiesandapplications . com/content/2012/1/72.

[7] C. P. CHEN AND W. S. Cheung, Inequalities and solution to Oppenheim's problem, Integral Transforms Spec. Funct. 23, 5 (2012), 325-336.

[8] C. P. CHEN AND J. SÁNDOR, Inequality chains for Wilker, Huygens and Lazarević type inequalities, J. Math. Inequal. 8, 1 (2014), 55-67.

[9] B. N. GuO, B. M. QIAO, F. QI AND W. Li, On new proofs of Wilker inequalities involving trigonometric functions, Math. Inequal. Appl. 6 (2003), 19-22.

[10] C. Huygens, Oeuvres Completes 1888-1940, Société Hollondaise des Science, Haga.

[11] B. J. MalešEvić, B. BAnJAC And I. Jovović, A proof of two conjectures of Chao-Ping Chen for inverse trigonometric functions, J. Math. Inequal. 11, 1 (2017), 151-162.

[12] D. S. Mitrinović, Analytic Inequalities, Springer-Verlag, Berlin, 1970.

[13] C. Mortici, The natural approach of Wilker-Cusa-Huygens inequalities, Math. Inequal. Appl. 14 (2011), 535-541.

[14] C. Mortici, A subtly analysis of Wilker inequality, Appl. Math. Comput. 231 (2014), 516-520.

[15] E. NEUMAN, One- and two-sided inequalities for Jacobian elliptic functions and related results, Integral Transforms Spec. Funct. 21 (2010), 399-407.

[16] E. Neuman, On Wilker and Huygens type inequalities, Math. Inequal. Appl. 15 (2012), 271-279.

[17] E. Neuman, Wilker and Huygens-type inequalities for the generalized trigonometric and for the generalized hyperbolic functions, Appl. Math. Comput. 230 (2014), 211-217.

[18] E. NEUMAN AND J. SÁNDOR, On some inequalities involving trigonometric and hyperbolic functions with emphasis on the Cusa-Huygens, Wilker, and Huygens inequalities, Math. Inequal. Appl. 13 (2010), 715-723. 
[19] I. Pinelis, L'Hospital rules of monotonicity and Wilker-Anglesio inequality, Amer. Math. Monthly, 111 (2004), 905-909.

[20] J. SÁNDOR AND M. BENCZE, On Huygens' trigonometric inequality, RGMIA Res. Rep. Collection 8, 3 (2005), Article 14.

[21] R. SRIVAStaVA, Some families of integral, trigonometric and other related inequalities, Appl. Math. Inform. Sci. 5 (2011), 342-360.

[22] J. S. Sumner, A. A. Jagers, M. Vowe And J. Anglesio, Inequalities involving trigonometric functions, Amer. Math. Monthly 98 (1991), 264-267.

[23] J. B. Wilker, Problem E 3306, Amer. Math. Monthly 96 (1989), 55.

[24] S. H. Wu, On extension and refinement of Wilker's inequality, Rocky Mountain J. Math. 39 (2009), 683-687.

[25] S. H. WU AND A. BARICZ, Generalizations of Mitrinović, Adamović and Lazarevic's inequalities and their applications, Publ. Math. Debrecen 75 (2009), 447-458.

[26] S. H. WU AND H. M. SRIVASTAVA, A weighted and exponential generalization of Wilker's inequality and its applications, Integral Transforms and Spec. Funct. 18 (2007), 529-535.

[27] S. H. WU AND H. M. SRIVASTAVA, A further refinement of Wilker's inequality, Integral Transforms and Spec. Funct. 19 (2008), 757-765.

[28] L. Zhang AND L. ZhU, A new elementary proof of Wilker's inequalities, Math. Inequal. Appl. 11 (2008), 149-151.

[29] L. ZHU, A new simple proof of Wilker's inequality, Math. Inequal. Appl. 8 (2005), 749-750.

[30] L. ZHU, On Wilker-type inequalities, Math. Inequal. Appl. 10 (2007), 727-731.

[31] L. ZHU, Some new Wilker-type inequalities for circular and hyperbolic functions, Abstr. Appl. Anal. 2009, Article ID 485842.

[32] L. ZHU, A source of inequalities for circular functions, Comput. Math. Appl. 58 (2009), 1998-2004.

[33] L. ZHU, Inequalities for Hyperbolic functions and their Applications, J. Inequal. Appl. 2010, Article ID 130821. 